\title{
KINERJA ASET RUANG MILIK JALAN PADA JALAN RUAS LINGKAR SELATAN KOTA SUKABUMI
}

\author{
Nurlaila Fadjarwati \\ Program Studi Manajemen Aset Politeknik Negeri Bandung \\ Corresponding Author Email : nurlaila.fadjarwati@polban.ac.id
}

ABSTRACT

According to Government Regulation No. 34/2006 about Roads, "Technical requirements for road must fulfil secure provision, safety and environmental conditions". In the last three years, there have been a number of accidents that have occurred on the South Ring Road Section, both causing serious injuries and death. The purpose of this study was to evaluate the road's space (Rumija) assets performance of Sukabumi City southern ring road based on the road usage dimensions and traffic safety on Sukabumi City South Ring Road. The research method used is a descriptive method with a qualitative approach. The data collection technique used is scientific observation. The results of this study, the performance of Rumija assets for the usage dimensions and safety is still lacking because, the road facilities in Rumija is incomplete and not all of them has functioning yet

Key word: Assets Performance, Rumija

\begin{abstract}
ABSTRAK
Menurut PP nomor 34 tahun 2006 Tentang Jalan, "Persyaratan teknis jalan harus memenuhi ketentuan aman, keselamatan dan lingkungan". Pada tiga tahun terakhir, masih ada beberapa kecelakaan yang terjadi di Jalan Ruas Lingkar Selatan baik yang menyebabkan luka berat maupun meninggal dunia. Tujuan penelitian ini untuk mengevaluasi kinerja aset ruang milik jalan ruas lingkar selatan Kota Sukabumi berdasarkan dimensi penggunaan jalan dan keamanan lalu lintas pada Jalan Ruas Lingkar Selatan Kota Sukabumi. Metode penelitian yang digunakan yakni metode deskriptif dengan pendekatan kualitatif. Teknik pengumpulan data yang digunakan yakni observasi ilmiah. Hasil dari penelitian ini, kinerja aset Rumija untuk dimensi penggunaan dan keamanan masih kurang karena, perlengkapan jalan pada rumija belum lengkap dan belum berfungsi semuanya .
\end{abstract}

Kata kunci: kinerja aset, Rumija 


\section{PENDAHULUAN}

Jalan Ruas Lingkar Selatan adalah ruas jalan arteri primer yang berada di Kota Sukabumi. Ruas lingkar selatan ini memiliki panjang jalan 11,7 km. Tujuan diadakan jalur ini adalah untuk mempermudah mobilitas masyarakat dari arah Bogor, Cicurug, Cibadak menuju Cianjur dan sebaliknya tanpa perlu melewati jalan-jalan Kota Sukabumi yang padat dan rawan terjadi kemacetan.

Menurut Peraturan Pemerintah nomor 34 tahun 2006 Tentang Jalan, pasal 12 ayat 2, "Persyaratan teknis jalan harus memenuhi ketentuan aman, keselamatan dan lingkungan". Pada tiga tahun terakhir, masih terjadi beberapa kecelakaan di Jalan Ruas Lingkar Selatan, baik yang menyebabkan luka berat maupun meninggal dunia. Untuk lebih jelasnya, data kecelakaan pada Jalan Ruas Lingkar Selatan, dapat dilihat Tabel 1 berikut ini.

Tabel 1 Data Kecelakaan

\begin{tabular}{lccc}
\hline Tahun & Meninggal Dunia & Luka Berat & Luka Ringan \\
\hline $\mathbf{2 0 1 7}$ & 1 & 1 & 11 \\
\hline $\mathbf{2 0 1 8}$ & 5 & - & 7 \\
\hline Hingga Juli 2019 & 9 & - & 14 \\
\hline Sumber: Laka Lantas Polresta Sukabumi, 2019 & &
\end{tabular}

Mengacu pada PP no 34 tahun 2006 tentang jalan, pasal 22 ayat 1 : "Persyaratan teknis jalan harus memenuhi ketentuan keamanan, keselamatan, dan lingkungan”. Selain itu, , menurut Undang-Undang no 38 tahun 2004 tentang Jalan, bahwa jalan sebagai bagian sistem transportasi mempunyai peranan penting terutama dalam mendukung pergerakan ekonomi, sosial budaya, politik, serta pertahanan dan keamanan. Untuk mendukung tercapainya peran penting jalan tersebut, jalan perlu dilengkapi dengan prasarana penunjang jalan yang memadai. Saat ini, prasarana penunjang jalan itu terasa kurang memadai. Misalnya, pada waktu malan hari, jalan tampak gelap, karena ada sebagian jalan belum ada Penerangan Jalan Umum (PJU) nya, sebagian lagi sudah ada PJU nya, tetapi di malam hari lampunya tidak menyala.

Berdasarkan pada hal-hal seperti yang telah diuraikan di atas, maka penelitian ini bertujuan untuk: mengevaluasi kinerja aset ruang milik jalan pada Ruas Llingkar Selatan Kota Sukabumi berdasarkan dimensi Infrastructure Utilizaton (Penggunaan Infrastruktur) dan Traffic safety (Keamanan Lalu Lintas). 


\section{TINJAUAN PUSTAKA}

\section{1) Definisi Manajemen Aset}

Hastings (2010) mendefinisikan manajemen aset sebagai hal yang berkaitan dengan praktik penilaian baik teknis, keuangan, maupun manajemen yang baik guna memutuskan aset apa yang dibutuhkan untuk mencapai tujuan bisnis. Setelah itu mengakuisisi aset secara berkelanjutan untuk mempertahankan aset selama-lamanya hingga saatnya penghapusan.

Selanjutnya, menurut Hastings (2010) Manajemen Aset meliputi serangkaian kegiatan yang terkait dengan: (1) Mengidentifikasi apa saja yang dibutuhkan aset, (2) Mengidentifikasi kebutuhan dana, (3) Memperoleh aset, (4) Menyediakan sistem dukungan logistic dan pemeliharaan untuk aset, (5) Menghapus atau memperbaharui aset secara efektif dan efisien sehingga dapat mencapai tujuan.

\section{2) Siklus Aset}

Siklus aset ini dimulai saat individu maupun organisasi merencanakan kebutuhan akan suatu aset sampai aset tersebut mengalami penurunan fungsi dan dilakukan penghapusan. Menurut Campbell (2011) siklus asset berawal dari melakukan penyusunan strategi pengelolaan aset yang bertujuan untuk menentukan segala hal yang dibutuhkan untuk mengelola aset. perencanaan asset (plan), evaluasi / desain asset (evaluate / design), membuat / mendapatkan asset (create / procure), mengoperasikan aset (operate), memelihara aset (maintain), memodifikasi aset (modify), menghapuskan aset (dispose), terus berulang hingga menjadi siklus aset. Adapula faktor yang mempengaruhi dan menjadi dasar dari siklus asset adalah manajemen keuangan (financial management) dan teknologi (technology).

Selain itu berdasarkan Peraturan Pemerintah Nomor 27 tahun 2014 terdapat 11 tahapan dalam siklus hidup aset. Tahapan-tahapan tersebut dimulai dari Perencanaan kebutuhan dan penganggaran, Pengadaan, Penggunaan, Pemanfaatan, Pengamanan dan Pemeliharaan, Penilaian, Pemindahtanganan, Pemusnahan, Penghapusan, Penatausahaan, Pembinaan, Pengawasan dan Pengendalian.

\section{3) Jenis-jenis Aset}

Menurut Campbell (2011), jenis aset dibedakan menjadi lima, yakni (1) Aset Real Estate dan Fasilitas; (2) Pabrik dan Produksi; (3) Aset bergerak; (4) Infrastruktur; (5) Teknologi Informasi. Aset Real Estate dan Fasilitas terdiri atas Tanah, Kantor, Gudang, 
Ruang Ritel, Sekolah, Perumahan, Rumah Sakit. Aset Pabrik dan Produksi terdiri atas Pertambangan, Semi-Konduktor, Tekstil, Kimia, Minyak Bumi, Elektronik, Makanan. Aset bergerak terdiri atas Aset Militer, Penerbangan, Truk, Perkapalan, Kereta Api, Aset Publik. Aset Teknologi Informasi terdiri atas Komputer, Router, Jaringan, Perangkat Lunak, Penemuan Otomatis, Meja Layanan. Aset Infrastruktur terdiri atas Kereta Api, Distribusi Listrik/Gas, Telekomunikasi, Air. Jalan Raya.

\section{4) Jalan}

Berdasarkan Peraturan Pemerintah nomor 34 tahun 2006 tentang jalan pasal 12 ayat 2 , jalan adalah prasarana transportasi darat yang meliputi segala bagian jalan, termasuk bangunan pelengkap dan perlengkapan yang diperuntukkan bagi lalu lintas yang berada pada permukaan tanah, di atas permukaan tanah, di bawah permukaan tanah dan atau air serta di atas permukaan air, kecuali jalan kereta api, jalan lori, dan jalan kabel.

\section{a. Bagian-Bagian Jalan}

Menurut Peraturan Pemerintah No 34 tahun 2006 Pasal 33, Bagian-bagian jalan meliputi ruang manfaat jalan (Rumaja), ruang pengawasan jalan(Ruwasja), dan ruang milik jalan (Rumija). Rumaja merupakan ruang sepanjang jalan yang dibatasi oleh lebar, tinggi, dan kedalaman tertentu yang ditetapkan oleh penyelenggara jalan yang bersangkutan. Rumaja meliputi badan jalan, saluran tepi jalan, dan ambang pengamanan.

Rumija merupakan ruang sepanjang jalan yang dibatasi oleh lebar, kedalaman, dan tinggi tertentu. Rumija diperuntukkan bagi ruang manfaat jalan, pelebaran jalan, dan penambahan jalur lalu lintas di masa yang akan datang, serta kebutuhan ruangan untuk pengamanan jalan.

Ruwasja merupakan ruang tertentu di luar Rumija yang penggunaannya ada di bawah pengawasan penyelenggara jalan. Ruwasja diperuntukkan bagi pandangan bebas pengemudi dan pengamanan konstruksi jalan serta pengamanan fungsi jalan.

\section{b. Perlengkapan jalan}

Merujuk pada Peraturan Menteri Pekerjaan Umum nomor 19 tahun 2011 tentang Persyaratan Teknis Jalan dan Kriteria Perencanaan Teknis Jalan, pasal 22 ayat 1, perlengakapan jalan yang bersifat wajib ada pada jalan meliputi: (1) aturan perintah dan larangan yang dinyatakan dengan rambu jalan, marka jalan, dan alat pemberi isyarat lalu lintas, (2) petunjuk dan peringatan yang dinyatakan dengan rambu dan tanda-tanda lain, (3) fasilitas pejalan kaki di jalan yang telah ditentukan. Sedangkan perlengkapan jalan yang 
tidak wajib ada adalah lampu penerangan jalan umum, kecuali pada (1) persimpangan, (2) tempat yang banyak pejalan kaki, (3) tempat parkir, daerah dengan jarak pandang yang terbatas.

\section{c. Kinerja Aset}

Setiap aset yang digunakan oleh setiap organisasi harus diukur kinerjanya. Menurut Victorian Government (1995), evaluasi aset menentukan apakah kinerja aset tersebut memadai untuk mencapai strategi yang telah ditetapkan. Evaluasi kinerja aset adalah peninjauan teratur terhadap tolak ukur performa aset untuk mengidentifikasi aset yang kinerjanya rendah atau berbiaya tinggi dalam pengoperasiannya

Pengukuran kinerja adalah serangkaian kegiatan untuk memastikan bahwa suatu organisasi dalam mencapai tujuan dan mengoptimalkan sumber daya yang dimiliki (NAO, 2016). Pada dasarnya, sebuah aset yang beroperasi harus dapat digunakan secara aman dan efektif. Untuk mencapai hal tersebut, perlu dilakukan kegiatan pemeliharaan agar aset dapat digunakan dalam kondisi yang sesuai dengan standar yang telah ditetapkan.

Menurut Australian Asset Management Collaborative Group (2008:1), mengukur kinerja aset harus sejalan dengan pengelolaan aset. Penerapan prinsip-prinsip manajemen aset memerlukan pendekatan berbasis kinerja pengelolaan aset, sehingga dapat memperkuat efektivitas dalam pengambilan keputusan internal maupun eksternal yang dapat dipertanggungjawabkan.

Pada Penelitian ini Pengukuran Kinerja Rumija merujuk pada jurnal Road Performance Mearurement System with Evaluation Instrument (KPI's) yang dapat dilihat pada Tabel 2 berikut ini:

Tabel 2 Kriteria Pengukuran Kinerja Ruang Milik Jalan

\begin{tabular}{|c|c|c|}
\hline No & Pengukuran Kinerja Menurut & $\begin{array}{l}\text { Kriteria Pengukuran } \\
\text { Kinerja yang digunakan } \\
\text { dalam Penelitian }\end{array}$ \\
\hline 1 & $\begin{array}{l}\text { Road technical condition } \\
\text { (Kondisi teknik jalan) adalah kondisi yang menunjukan tinkat } \\
\text { kerusakan }\end{array}$ & - \\
\hline 2 & $\begin{array}{l}\text { Infrastructure utilization } \\
\text { (Penggunaan infrastruktur) adalah sarana prasarana jalan yang } \\
\text { digunakan sesuai TUPOKSI }\end{array}$ & $\checkmark$ \\
\hline 3. & $\begin{array}{l}\text { Traffic density } \\
\text { (Kepadatan lalu lintas) adalah jumlah tingkat kepadatan } \\
\text { pengguna jalan saat lalu lintas }\end{array}$ & - \\
\hline 4. & $\begin{array}{l}\text { Traffic safety } \\
\text { (Kamanan lalu lintas) } \\
\text { Keamanan berlalu lintas untuk pengguna jalan }\end{array}$ & $\checkmark$ \\
\hline
\end{tabular}




\section{METODE PENELITIAN}

Pendekatan kualitatif adalah suatu prosedur penelitian yang dirancang untuk menjelaskan bagaimana proses dan alasan suatu peristiwa dapat terjadi (Cooper \& Schindler, 2014). Pada penelitian ini pendekatan penelitian kualitatif dipakai guna memberikan gambaran secara deskriptif dan jelas terhadap fenomena yang dikaji terkait kinerja keselamatan aset Jalan Ruas Lingkar Selatan Kota Sukabumi.

Menurut Sekaran (2003:119), terdapat empat jenis metode penelitian, yaitu penelitian eksploratori, deskriptif, uji hipotesis, dan analisis studi kasus. Dalam penelitian ini, metode yang digunakan yaitu metode penelitian deskriptif. Sementara menurut Sugiyono (2003:11) penelitian deskriptif adalah penelitian yang dilakukan untuk mengetahui nilai variabel mandiri, baik satu variabel atau lebih (independen) tanpa membuat perbandingan, atau menghubungkan dengan vaiabel lain. Teknik pengumpulan data yang digunakan adalah observasi ilmiah di sepanjang Ruas Jalan Lingkar Selatan Sukabumi.

\section{a. Operasional Variabel}

Operasional Variabel memungkinkan bagi peneliti untuk mengembangkan cara bagaimana mengukur construct yang lebih baik dengan suatu cara tertentu. Rincian mengenai operasioal Variabel dapat dilihat pada tabel 3 berikut ini: 
Tabel 3. Operasional Variabel

\begin{tabular}{|c|c|c|c|c|}
\hline Variabel & Sub Variabel & Indikator & Pertanyaan/Pernyataan & $\begin{array}{c}\text { Teknik } \\
\text { Pengumpulan } \\
\text { Data }\end{array}$ \\
\hline \multirow{16}{*}{$\begin{array}{l}\text { Kinerja Aset } \\
\text { Peninjauan teratur } \\
\text { terhadap tolak } \\
\text { ukur performa } \\
\text { aset untuk } \\
\text { mengidentifikasi } \\
\text { aset yang } \\
\text { kinerjanya rendah } \\
\text { atau berbiaya } \\
\text { tinggi dalam } \\
\text { pengoperasiannya } \\
\text { (Victoria } \\
\text { Government, } \\
\text { 1995). }\end{array}$} & \multirow{12}{*}{$\begin{array}{l}\text { 1. Infrastructure } \\
\text { utilization } \\
\text { (Penggunaan } \\
\text { infrastruktur) } \\
\text { adalah sarana } \\
\text { prasarana jalan } \\
\text { yang digunakan } \\
\text { sesuai TUPOKSI } \\
\text { (K. Kõrbe Kaare, } \\
\text { dan O. Koppel, } \\
\text { 2012). }\end{array}$} & \multirow{3}{*}{$\begin{array}{l}\text { 1. Alat } \\
\text { pemberi } \\
\text { isyarat lalu } \\
\text { lintas (APILL) }\end{array}$} & $\begin{array}{l}\text { 1. Apakah sudah tersedia } \\
\text { APILL di Ruas Lingkar } \\
\text { Selatan? }\end{array}$ & Observasi \\
\hline & & & $\begin{array}{l}\text { 2. Apakah APILL yang } \\
\text { tersedia sudah sesuai } \\
\text { dengan tupoksinya? }\end{array}$ & Observasi \\
\hline & & & $\begin{array}{l}\text { 3. APILL dalam kondisi } \\
\text { baik }\end{array}$ & Observasi \\
\hline & & \multirow[t]{3}{*}{$\begin{array}{l}\text { 2. Rambu Lalu } \\
\text { lintas }\end{array}$} & $\begin{array}{l}\text { 1. Apakah sudah tersedia } \\
\text { Rambu Lalu Lintas di Ruas } \\
\text { Lingkar Selatan? }\end{array}$ & Observasi \\
\hline & & & $\begin{array}{l}\text { 2.Apakah APILL yang } \\
\text { tersedia sudah sesuai } \\
\text { dengan tupoksi? }\end{array}$ & Observasi \\
\hline & & & $\begin{array}{l}\text { 3. Rambu lalu lintas dalam } \\
\text { kondisi baik }\end{array}$ & Observasi \\
\hline & & \multirow[t]{3}{*}{$\begin{array}{l}\text { 3. Penerangan } \\
\text { jalan umum } \\
\text { (PJU) }\end{array}$} & $\begin{array}{l}\text { 1. Apakah sudah tersedia } \\
\text { PJU di Ruas Lingkar } \\
\text { Selatan? }\end{array}$ & Observasi \\
\hline & & & $\begin{array}{l}\text { 2. Apakah PJU yang } \\
\text { tersedia sudah sesuai } \\
\text { dengan tupoksi? }\end{array}$ & Observasi \\
\hline & & & 3. PJU dalam kondisi baik & Observasi \\
\hline & & \multirow[t]{3}{*}{ 1. Trotoar } & $\begin{array}{l}\text { 1. Apakah sudah tersedia } \\
\text { PJU di Ruas Lingkar } \\
\text { Selatan? }\end{array}$ & Observasi \\
\hline & & & $\begin{array}{l}\text { 2. Apakah PJU yang } \\
\text { tersedia sudah sesuai } \\
\text { dengan tupoksinya? }\end{array}$ & Observasi \\
\hline & & & 3. PJU dalam kondisi baik & Observasi \\
\hline & \multirow{4}{*}{$\begin{array}{l}\text { 2.1 Traffic } \\
\text { safety } \\
\text { (Keamanan lalu } \\
\text { lintas) Keamanan } \\
\text { berlalu lintas } \\
\text { untuk pengguna } \\
\text { jalan (K. Kõrbe } \\
\text { Kaare, dan O. } \\
\text { Koppel, 2012). }\end{array}$} & $\begin{array}{l}\text { 1. Alat } \\
\text { pemberi } \\
\text { isyarat lalu } \\
\text { lintas (APILL) }\end{array}$ & $\begin{array}{l}\text { Apakah APILL aman saat } \\
\text { digunakan? }\end{array}$ & Observasi \\
\hline & & $\begin{array}{l}\text { 2. Rambu Lalu } \\
\text { lintas }\end{array}$ & $\begin{array}{l}\text { Apakah Rambu Lalu Lintas } \\
\text { aman saat digunakan? }\end{array}$ & Observasi \\
\hline & & $\begin{array}{l}\text { 3. Penerangan } \\
\text { jalan umum }\end{array}$ & $\begin{array}{l}\text { Apakah PJU aman saat } \\
\text { digunakan? }\end{array}$ & Observasi \\
\hline & & 4. Trotoar & $\begin{array}{l}\text { Apakah Trotoar aman saat } \\
\text { digunakan? }\end{array}$ & Observasi \\
\hline
\end{tabular}

Sumber: Olah Data Peneliti, 2019 


\section{PEMBAHASAN}

Berdasarkan hasil observasi, maka diperoleh hasil evaluasi bahwa kinerja aset Ruang Milik Jalan (Rumija) Jalan Ruas Lingkar Selatan Kota Sukabumi. Hasil dan pembahasannya akan disampaikan berikut ini.

\section{A. Infrastructure utilization (Penggunaan infrastruktur)}

1) Alat Pemberi Isyarat Lalu Lintas (APILL)

Menurut hasil observasi ruas lingkar selatan terdapat 13 buah APILL satu warna, dan 3 APILL tiga warna. Pada ruas jalan ini kondisi 8 APILL satu warna menyala, 5 buah lampu APILL satu warna dalam kondisi lampu yang tidak menyala. Menurut Peraturan Menteri Perhubungan Nomor PM 49 Tahun 2014 Pasal 1 ayat (1) APILL berfungsi untuk memberi peringatan bahaya dan mengatur lalu lintas. Namun kondisi jenis lampu satu warna untuk memberikan peringatan bahaya yang ada di Jalan Ruas Lingkar selatan Kota Sukabumi sebagian besar tidak berfungsi. Berikut adalah kondisi APILL di Jalan Ruas Lingkar Selatan.

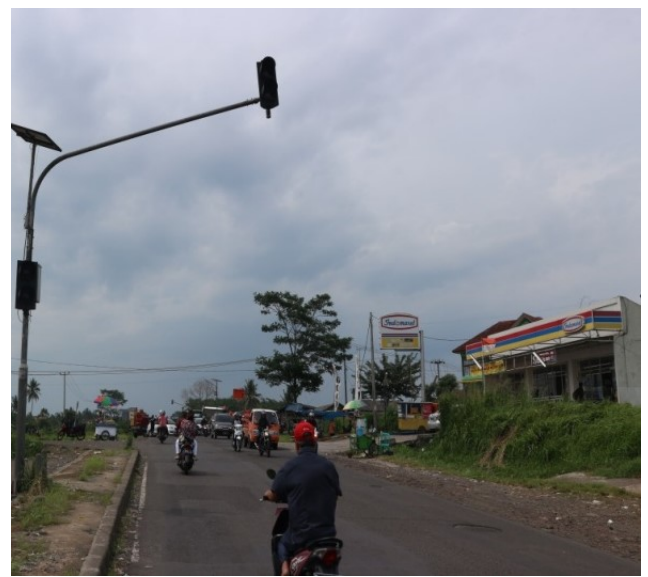

Gambar 2 Kondisi APILL

Sumber : Dokumentasi Peneliti, 2019

APILL yang ada terletak pada titik lokasi seperti sekolah, tempat ibadah, kantor pelayanan masyarakat, kantor lembaga pemerintah, dan persimpangan, dimana membutuhkan kewaspadaan bagi pengemudi atau pengguna jalan.

2) Rambu Lalu Lintas

Berdasarkan hasil observasi, Rambu yang ada di Jalan Ruas Lingkar Selatan masih belum lengkap. Tidak terdapat rambu persimpangan tiga serong, persimpangan 4 arah, area banyak lalu lintas kendaraan besar, dan penyeberangan pejalan kaki. Menurut Peraturan 
Menteri Perhubungan Republik Indonesia No. PM 13 Tahun 2014 Tentang Rambu Lalu Lintas Pasal 1, daun rambu merupakan pelat alumunium atau bahan lainnya yang memenuhi persyaratan teknis tempat ditempelkan/dilekatkannya rambu. Daun rambu dilengkapi dengan simbol yang terdapat Retro Reflektif sehingga dapat memantulkan cahaya pada arah sinar datang terutama pada malam hari. Namun pada kenyatannya, masih terdapat daun rambu yang terbuat dari kertas banner, dimana simbol yang ada pada daun rambu belum menggunakan Retro Reflektif sehingga tidak dapat memantulkan simbol informasi rambu.

Selain itu kondisi tiang rambu yang ada di Jalan Ruas Lingkar Selatan sudah miring dan dapat membahayakan aktifitas pengguna jalan. Sehingga perlu adanya perbaikan dan pemeliharaan pada tiang rambu di ruas lingkar selatan. Gambar 3 berikut ini adalah kondisi satu tiang pada Jalan Ruas Lingkar Selatan Kota Sukabumi.

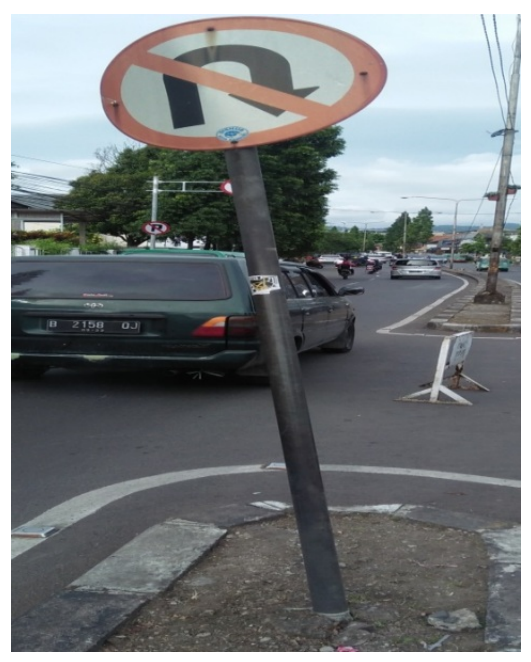

Gambar 3 Kondisi Tiang Rambu Sumber : Dokumentasi Pribadi, 2019

3) Penerangan Jalan Umum (PJU)

Berdasarkan hasil observasi peneliti, total PJU yang terpasang di Jalan Ruas Lingkar Selatan Kota Sukabumi sebanyak 176 PJU. Namun, tidak semua PJU dapat berfungsi , karena pada malam hari lampunya tidak menyala. Contoh kondisi PJU yang tidak dapat menyala di malam hari dapat dilihat pada gambar 4 berikut ini.

Tidak menyalanya sebagian PJU tersebut membuat tingkat fungsionalitas dari PJU rendah. PJU tidak bisa menjalankan fungsi sesuai dengan tupoksinya. Selain itu jarak pemasangan tiang PJU yang satu dengan yang lainnya tidak beraturan. 


\section{4) Trotoar}

Menurut Permen PU No 19/PRT/M Tahun 2011 Pasal 29 bahwa trotoar harus memenuhi kebutuhan untuk pejalan kaki. Gambar 5 berikut ini adalah kondisi sebagian trotoar yang rusak.

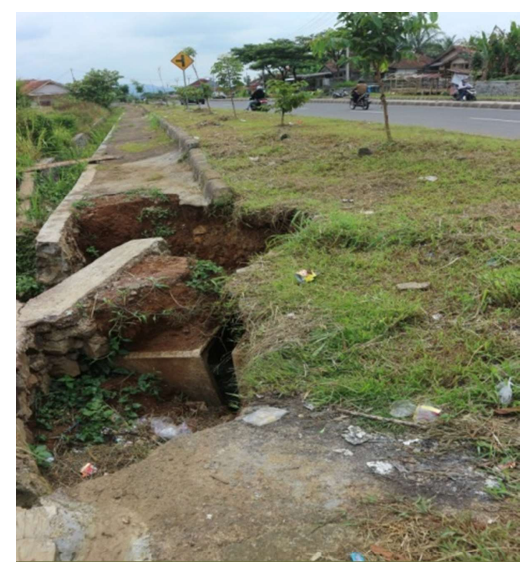

Gambar 4 Kondisi Trotoar

Sumber: Dokumentasi pribadi

Kondisi trotoar yang ada di Jalan Ruas Lingkar Selatan Kota Sukabumi banyak yang mengalami kerusakan. Hal tersebut dapat mengganggu kenyamanan pejalan kaki. Berdasarkan hasil evaluasi kinerja dari dimensi penggunaan infrastruktur, pada ke empat indikatornya mengalami kerusakan dan belum sesuai dengan peraturan yang berlaku. Hal itu dapat dilihat pada table 4 berikut ini.

Tabel 4 Hasil Evaluasi Kinerja Aspek Infrastructure utilization (Penggunaan infrastruktur)

\begin{tabular}{|c|c|c|c|}
\hline No & Indikator & Kondisi & Keterangan \\
\hline 1. & $\begin{array}{l}\text { Alat Pemberi Isyarat } \\
\text { Lalu Lintas (APILL) }\end{array}$ & $\begin{array}{l}\text { Belum } \\
\text { Sesuai }\end{array}$ & sebagian besar APILL tidak berfungsi \\
\hline 2. & Rambu Lalu Lintas & $\begin{array}{l}\text { Belum } \\
\text { Sesuai }\end{array}$ & $\begin{array}{l}\text { Sebagian rambu tiangnya perlu diperbaiki dan rambu } \\
\text { belum menggunakan Retro Reflektif. }\end{array}$ \\
\hline 3. & $\begin{array}{l}\text { Penerangan Jalan } \\
\text { Umum (PJU) }\end{array}$ & $\begin{array}{l}\text { Belum } \\
\text { Sesuai }\end{array}$ & $\begin{array}{l}\text { Pada malam hari sebagian PJU tidak menyala, dan } \\
\text { jarak pemasangan tiang PJU belum teratur. }\end{array}$ \\
\hline 4. & Trotoar & $\begin{array}{l}\text { Belum } \\
\text { Sesuai }\end{array}$ & Trotoar pada sebagian ruas jalan rusak berat. \\
\hline
\end{tabular}

B. Traffic safety (Keamanan lalu lintas)

1) Alat Pemberi Isyarat Lalu Lintas (APILL)

APILL seharusnya dipasang pada persimpangan jalan, tempat penyeberangan pejalan kaki (zebra cross), dan tempat arus lalu lintas lainnya. Lampu ini yang 
menandakan kapan kendaraan harus berjalan dan berhenti secara bergantian dari berbagai arah lalu lintas.

Salah satu persimpangan jalan yang ada belum memiliki APILL. Hal tersebut mengakibatkan kemacetan dan mengganggu pergerakan kendaraan.

2) Rambu Lalu Lintas

Berdasarkan hasil observasi, Jalan Ruas Lingkar Selatan masih kekurangan rambu. Beberapa lokasi seperti tikungan, area sekolah, tempat ibadah belum diberi rambu. Rambu larangan berupa batas maksimal kecepatan pun belum ada, sehingga pengendara banyak yang melaju dengan kecepatan tinggi. Pemenuhan fungsi rambu lalu lintas pada ruas lingkar selatan dapat dilihat pada tabel 5 berikut ini.

Tabel 5 Pemenuhan fungsi rambu lalu lintas

\begin{tabular}{lll}
\hline No & Jenis Rambu & \multicolumn{1}{c}{ Kondisi rambu } \\
\hline 1. & $\begin{array}{l}\text { Rambu } \\
\text { peringatan }\end{array}$ & Belum memenuhi, masih kurangnya rambu peringatan \\
\hline 2. & Rambu larangan & $\begin{array}{l}\text { Belum memenuhi, karena masih kurangnya rambu larangan sehingga } \\
\text { pengguna jalan tidak mengetahui larangan pada lokasi tertentu }\end{array}$ \\
\hline 3. & Rambu Perintah & Belum memenuhi, karena masih kurangnya rambu perintah \\
\hline 4. & Rambu petunjuk & Sudah memenuhi, karena 100\% rambu berfungsi dengan baik \\
\hline
\end{tabular}

Rambu lalu lintas pada Jalan Ruas Lingkar Selatan belum berfungsi dengan baik. Hal ini dikarenakan kurangnya rambu yang terpasang, sehingga pengendara banyak yang melaju dengan kecepatan tinggi dan dapat mengakibatkan kecelakaan lalu lintas.

\section{3) Penerangan Jalan Umum (PJU)}

Menurut SNI 7391 Tahun 2008 PJU harus mendukung kenyamanan dan keselamatan serta keamanan lingkungan khususnya pada malam hari. Penerangan Jalan Umum (PJU) memberi peran penting sebagai alat bantu navigasi pengguna jalan. Berdasarkan observasi, sebagian besar PJU yang ada saat ini belum memenuhi fungsi PJU yang seharusnya, yaitu memberikan keselamatan, keamanan, dan navigasi bagi pengguna jalan terutama di malam hari. Gelapnya jalan pada malam hari dapat menimbulkan kecelakaan lalu lintas. Kurangnya terpenuhinya PJU dapat dilihat pada gambar 8 berikut ini. 


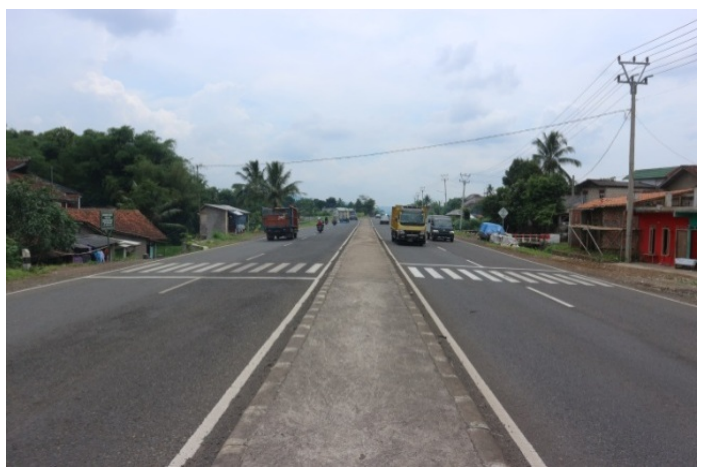

Gambar 7 Kondisi kurangnya PJU

Sumber: Dokumentasi pribadi, 2019

\section{4) Trotoar}

Menurut Dirjen Bina Marga Nomor 011/T/Bt/1995 suatu ruas jalan dianggap perlu dilengkapi dengan trotoar apabila di sepanjang jalan tersebut terdapat penggunaan lahan yang mempunyai potensi adanya pejalan kaki. Penggunaan lahan tersebut antara lain perumahan ,sekolah, pusat perbelanjaan, pusat perdagangan, pusat perkantoran, pusat hiburan, pusat kegiatan sosial, daerah industri, terminal bus dan lain-lain. Berdasarkan hasil observasi, Jalan Ruas Lingkar Selatan berada dekat dengan pemukiman, sekolah, dan terminal bus. Banyak pejalan kaki yang melewati Jalan Ruas Lingkar Selatan Selain itu volume lalu lintas di ruas lingkar selatan lebih dari 1000 kendaraan per 12 jam sehingga diperlukan trotoar di ruas lingkar selatan.

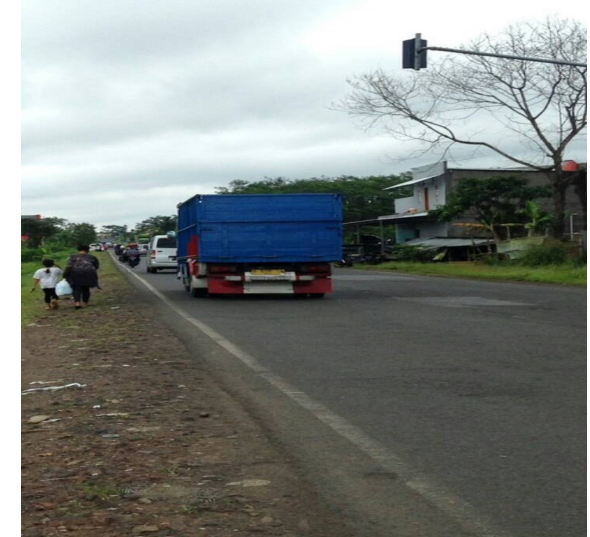

Gambar 8 Kondisi Jalan Tanpa Trotoar Sumber: Dokumentasi pribadi, 2019

Gambar 8 menunjukkan tidak adanya trotoar di sebagian Jalan Ruas Lingkar Selatan.. Berdasarkan hasil wawancara, kendaraan yang melewati ruas lingkar selatan melaju dengan kecepatan tinggi. Karena banyaknya kendaraan yang melewati Jalan Ruas 
Lingkar Selatan, maka pengendara sering menggunakan bahu jalan untuk berlalu lintas. Hal tersebut dapat membahayakan para pejalan kaki karena.

Berdasarkan hasil evaluasi kinerja aset dari dimensi traffic safety diperoleh data seperti pada table 6 berikut ini.

Tabel 6 Hasil Evaluasi Kinerja Aspek Traffic Safety (Keamanan lalu lintas)

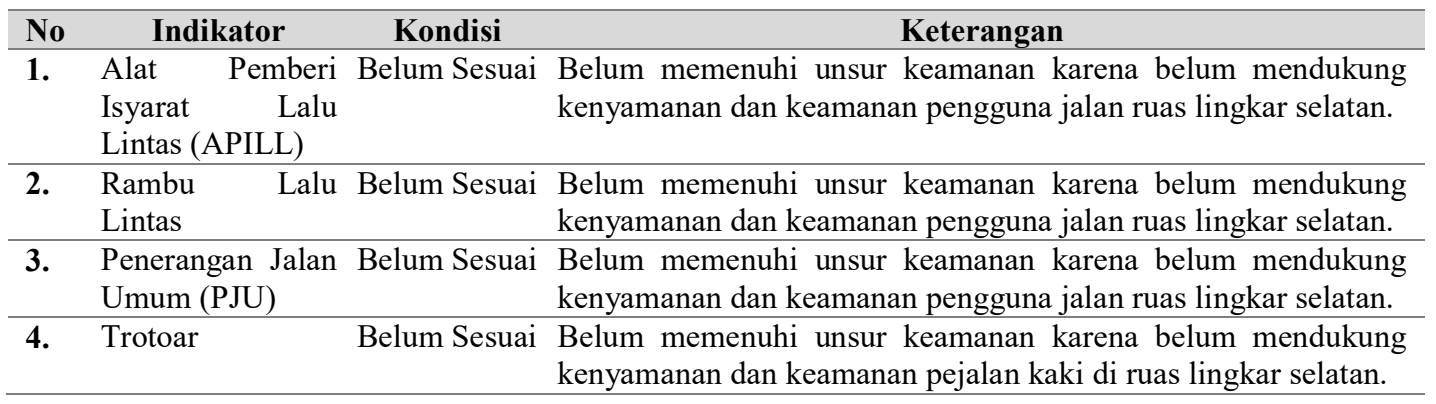

\section{KESIMPULAN DAN SARAN}

\section{Kesimpulan}

Berdasarkan pembahasan di atas, hasil penelitian ini dapat disimpulkan sebagai berikut:

1) Kinerja aset rumija pada dimensi infrastructure utilization (penggunaan infrastruktur) yakni APILL, rambu lalu lintas, PJU, dan trotoar masih rendah karena keberadaannya belum memenuhi kebutuhan.

2) Aset rumija belum memenuhi unsur keamanan yang dapat mendukung kenyamanan dan keamanan pengguna jalan, karena jumlah dan kualitas APILL belum cukup. Selain itu PJU dan trotoarpun masih banyak yang rusak atau belum tersedia.

\section{Saran}

Berdasarkan kesimpulan di atas, maka disarankan dilakukannya rehabilitasi aset Rumija agar dapat meningkatkan kinerja Rumija pada dimensi Penggunaan Infrastruktur dan Keamanan Lalu-lintas. Dengan rehabilitasi aset Rumija, maka permasalahan seperti yang telah diuraikan akan dapat diselesaikan karena kebutuhan pelengkap jalan pada Rumija Jalan Ruas Lingkar Selatan Kota Sukabumi dapat dipenuhi..

\section{DAFTAR PUSTAKA}

Campbell, John.D, dkk., (2011), Second Edition Asset Management Excellence Optimizing Equipment Life Cycle Decisions, USA: Taylor \& Francis Group. 
Cooper \& Schindler. (2014). Business mesearch methods: twelfth edition. New York: McGraw-Hill/Irwin.

Hastings, Nicholas Anthony John (2010:4). Physical Asset Management - Nicholas Anthony John Hastings. Australia: Springer.

Hermanto, Agus. 2009. Pengelolaan Barang Milik Negara. Jakarta : Dapartemen Keuangan Republik Indonesia Badan Pendidikan dan Pelatihan keuangan Umum.

Illuminating Engineering Society. 2000. The IESNA Lighting Hand Book Ninth Edition. North America: IESNA (Illuminating Engineering Society Of North America).

K. Kõrbe Kaare, and O. Koppel, "Improving the Road Construction Supply Chain by Developing a National Level Performance Measurement System: the Case of Estonia”, International Journal of Social and Human Sciences, no.6, pp. 225-231, 2012.

Sekaran, Uma. (2006). Metodologi Penelitian untuk Bisnis. Jakarta: Salemba Empat.

Siregar, Doli D., (2004), Manajemen Aset, Jakarta: PT. Gramedia Pustaka Utama.

Sugiama, A Gima (2013), Manajemen Aset Pariwisata Pelayanan Berkualitas agar Wisatawan Puas dan Loyal, Bandung: Guardaya Intimarta.

UK Government. (2007), Manual for Streets. London : Thomas Telford Publishing.

Undang-Undang Republik Indonesia No 38 Tahun 2004 Tentang Jalan.

Peraturan Pemerintah No 34 Tahun 2006 Tentang Jalan.

Peraturan Menteri Pekerjaan Umum No 19 Tahun 2011 Tentang Persyaratan Teknis Jalan dan Kriteria Perencanaan Teknis Jalan

Peraturan Menteri Perhubungan Republik Indonesia Nomor PM 13 Tahun 2014 Tentang Rambu Lalu Lintas

Peraturan Menteri Perhubungan Nomor PM 49 Tahun 2014 Tentang Alat Pemberi Isyarat Lalu Lintas

Direktorat Jendral Bina Marga Nomor 011/T/Bt/1995 Tentang Trotoar

Departemen Permukiman dan Prasarana Wilayah Tahun 2004 Tentang Marka Jalan

Dapertemen Pekerjaan Umum Tahun 1997 Tentang Bahu Jalan

Dapartemen Pekerjaan Umum Tahun 2016 Tentang Drainase Jalan

Badan Standar Nasional, SNI 7391: 2008, Spesifikasi penerangan jalan di kawasan perkotaan 